\title{
Effects of a mobility monitoring system on the cost of care in relation to reimbursement at Swiss nursing homes: learnings from a randomized controlled trial
}

\author{
Mario Stark ${ }^{1^{*}} \mathbb{D}$, Rigo Tietz ${ }^{1}$, Heidrun Gattinger ${ }^{2}$, Virpi Hantikainen ${ }^{2}$ and Stefan Ott ${ }^{3}$
}

\begin{abstract}
Background/objective: Nursing homes in Switzerland are under pressure to efficiently coordinate staff activities to cover their personnel costs under the care financing system. In this study, the use of a mobility monitoring system accompanied with case conferences was investigated in order to improve sleep quality and estimate the cost benefit of this intervention.

Method: In an open two-phase randomized controlled trial at three nursing homes, residents with cognitive impairment were randomly assigned to an intervention group and a control group. In the intervention group, a 10-week period of intensive use of the monitoring system and case conferences led by an advanced nurse practitioner (Phase I) was followed by 3 months of reduced use of the monitoring system and case conferences led by an internal registered nurse (Phase II). In the control group, the monitoring system was only used for data acquisition. Nurses reported the activities with a specifically developed tool. Based on the recorded activities, the cost of care was calculated. The correlating reimbursement per patient was calculated from the care levels in the Swiss reimbursement system. Data from 44 residents was included in the analysis with a linear mixed model.
\end{abstract}

Results: Although analysis revealed no statistically significant effects, results indicate that the use of a monitoring system can guide nurses in organizing their tasks to increase effectiveness. Information systems such as the mobility monitor can help to identify single outliers that do not correspond with the overall situation.

Conclusion: In the health care system, problematic individual cases can account for a disproportionally high cost levels. It was shown that information systems can have a significant economic impact in the long run.

Trial registration: The study is registered at the German Clinical Trials Register under the Nr. DRKS-ID: DRKS00006829.

Keywords: Health economics, Cost of care, Reimbursement, Monitoring system, Nursing home

\footnotetext{
* Correspondence: mario.stark@fhsg.ch

'Institute of Business Management, University of Applied Sciences St. Gallen,

Rosenbergstrasse 59, Postfach, 9001 St. Gallen, Switzerland

Full list of author information is available at the end of the article
} 


\section{Background}

\section{Challenges of cost efficiency in nursing homes}

Swiss nursing homes struggle with the cost limitation policies imposed by local and regional constituencies [1]. Large differences also exist in the costs of care per day between the different cantons (Fig. 1; source: [2]). Hence, there is room for improvement in specific institutions. Crivelli et al. [3] investigated the relationship between cost efficiency, the alternative institutional forms, and the different regulatory settings. Their results "showed that only approximately $60 \%$ of the nursing homes included in our sample operate close to the national standard for efficiency." In an earlier study, Fillipini [4] found that economies of scale exist for most output levels at Swiss nursing homes in the Ticino. The study could not identify if the effects are more due to potential savings in the cost of direct care or in infrastructure cost.

A growing number of new technologies are becoming available within nursing care. These can improve the quality of care, reduce costs, or enhance working conditions [5]. To date, most studies have focused on the effect of electronic medical record (EMR) systems on cost and quality of care. For instance, Hitt and Tambe [6] investigated the relationship between the use of electronic medical record (EMR) systems and nursing home performance. They found a positive effect of EMR-system implementation, about $1 \%$ higher productivity, $3 \%$ greater efficiency, but approximately $2.7 \%$ higher cost. Therefore, the economic effect of the introduction of EMR might be questionable.

\section{New technologies for monitoring of residents}

However, there are many different approaches to using new technology to improve efficiency in nursing homes.
In a study performed at a retirement community in Missouri, Rantz et al. [7] used environmentally embedded sensor systems to create automated health alerts. Results indicated that residents living with sensors were able to reside 1.7 years longer than residents living without sensors, suggesting that proactive use of health alerts facilitates successful aging. Cost estimates revealed potential savings in labor cost of about USD 30'000 per person, based on the improved coordination of care by the nurses.

Beaty and Sauer [8] showed that the use of a smart bed technology reduced new pressure ulcers by $85 \%$ in new pressure ulcer development. An additional economic analysis resulted in estimated net savings of USD 9.06 to 14.70 per bed per day.

Slight et al. [9] equipped a community hospital with a monitoring unit that measures mechanical vibrations of the heart cardio ballistic motion effect, respiratory and patient motion. "Average net benefit of implementing the system ranged from $\$ 224$ per patient [...] to $\$ 710$ per patient." It was therefore concluded that the implementation of this monitoring system resulted in a positive return on investment.

In the study discussed here, the use of a mobility monitoring system accompanied with case conferences was investigated to improve sleep quality in nursing home residents with cognitive impairment. The design and the sample of the study are reported in detail elsewhere [10]. While sleep quality in the intervention group increased, sleep quality in the control group remained almost stable. Results indicate that using a mobility monitoring system can improve the assessment of nighttime mobility and activity and support nurses in planning and implementing care interventions (repositioning, continence care, and inspection rounds). In parallel, the

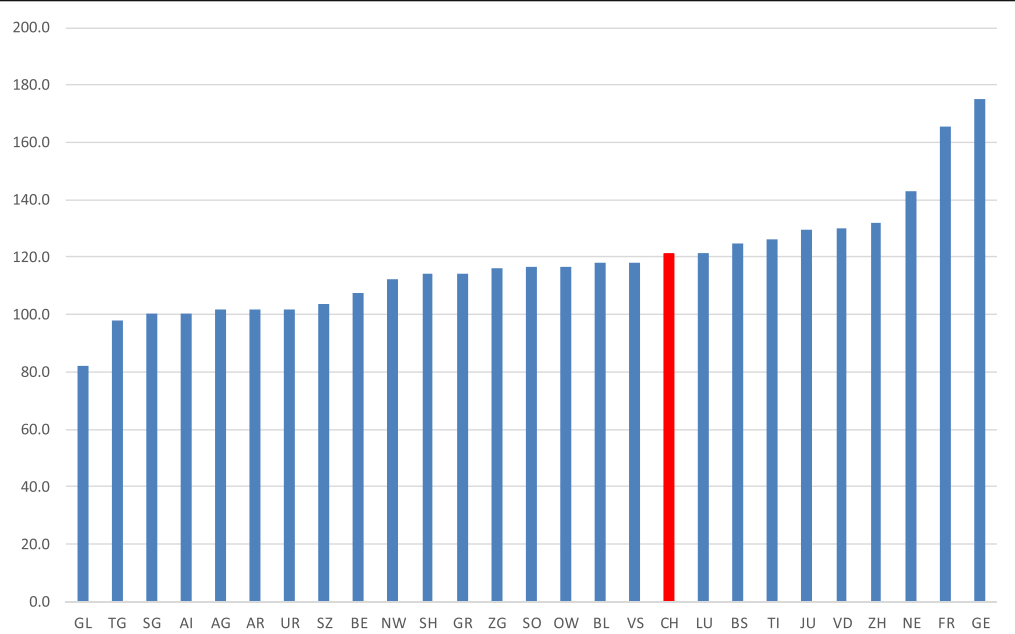

Fig. 1 Cost of Care per Day in Switzerland. Average cost of care in nursing homes per day (y-axis) compared between the different cantons of Switzerland (x-axis). All numbers in CHF. Swiss average highlighted in red 
influence on cost of care was assessed. The results of these health economic evaluations are presented here.

\section{Methods}

The study protocol was approved by the responsible ethics review committee (EKSG 14/101).

\section{Design}

This study was designed as an open two-phase randomized controlled trial. It was conducted at 11 wards in a convenience sample of three nursing homes between November 2014 and September 2015. A 10-week period of intensive use of the monitoring system and case conferences led by an advanced nurse practitioner (Phase I) was followed by 3 months of reduced use of the monitoring system and case conferences led by an internal registered nurse (Phase II). Randomization at the level of nursing home wards was chosen to prevent contamination between intervention and control participants. Simple randomization was used to assign the wards to the intervention and control group. Data collection took place at baseline $\left(T_{0}\right)$, after Phase I $\left(T_{1}=10\right.$ weeks after intervention started), and after Phase II $\left(\mathrm{T}_{2}=6\right.$ months after intervention started). The patient flow can be seen in Fig. 2.

\section{Setting and participants}

Three medium-sized nursing homes in Germanspeaking Switzerland participated in the study. Within the nursing homes, all wards and all affiliated qualified nurses and student nurses were involved. To be eligible for the study, nursing home residents had to suffer from cognitive impairment and sleeping disorders. Thirty-two women and 12 men with a mean age of 87.5 years (SD: 7.1) were included. Residents' mean duration of stay at the beginning of the study was 40.8 months (SD: 32.9 ). On average, $20.5 \%$ of participants fell into care levels 14, 59.0\% into care levels 5-8, and $20.5 \%$ into care levels 9-12. Inclusion criteria and demographic data are described in more detail in Gattinger et al. [10].

\section{Intervention}

Interventions included in-house training on the monitoring system and interpretation of the data gathered by the system. In each institution, one or two nurses were trained as key-users to support other nurses if questions arose about the monitoring system. In addition, in-house training on dementia and sleep was provided.

The situation of each participating resident was discussed during case conferences. A case conference is defined as a goal-oriented, systematic method that team members can use to exchange professional opinions on a particular care problem. Case conferences can be a valid tool for nursing home staff to deal professionally with individual residents' sleep disturbances. Case conferences are particularly useful for understanding difficult situations.

In the intervention group, monitoring data was included in the discussion. In Phase I, three case conferences per nursing home resident were conducted. Case conferences were led by an external advanced nurse practitioner. In phase II, two case conferences per nursing home resident led by an internal registered nurse were conducted. The discussed problems, favored outcomes, and planned interventions were recorded.

\section{Use of the monitoring system}

The monitoring system used in this study is an in-bed system that records mobility and micro-activity without any body contact. It includes warnings in cases of immobility with individually adjustable tolerance $(2 \mathrm{~h}, 3 \mathrm{~h}$, $4 \mathrm{~h}$ ). In addition, a bed-exit alarm can be activated. Data is continuously wirelessly transmitted, stored and analyzed with dedicated software.

Individual mobility profiles were used to assess resident activity and movement patterns and to support nurses' decision whether to initiate a sleep-promoting intervention. The data and the warning system were also used to establish whether residents needed to be moved due to decubitus prophylaxis.

\section{Instruments used to assess care activities}

Nurses' daytime and nighttime activities were recorded using a self-developed assessment tool designed for economic assessment.

The following daytime activities were recorded:

- Changing position in bed as decubitus prophylaxis

- Transfer from or into the bed, wheelchair, or into a sitting position

- Accompanied walking in the resident's room

- Accompanied walking outside the resident's room

- Support with going to the toilet

- In addition, any aids used were recorded (positioning aids, security bars around the bed or bell mats)

The following nighttime activities were recorded:

- Check-up visits

- Changing position in bed as decubitus prophylaxis

- Support with going to the toilet

- Incontinence care

- Other activities as stated

- In addition, any aids used were recorded (positioning aids, security bars around the bed or bell mats) 


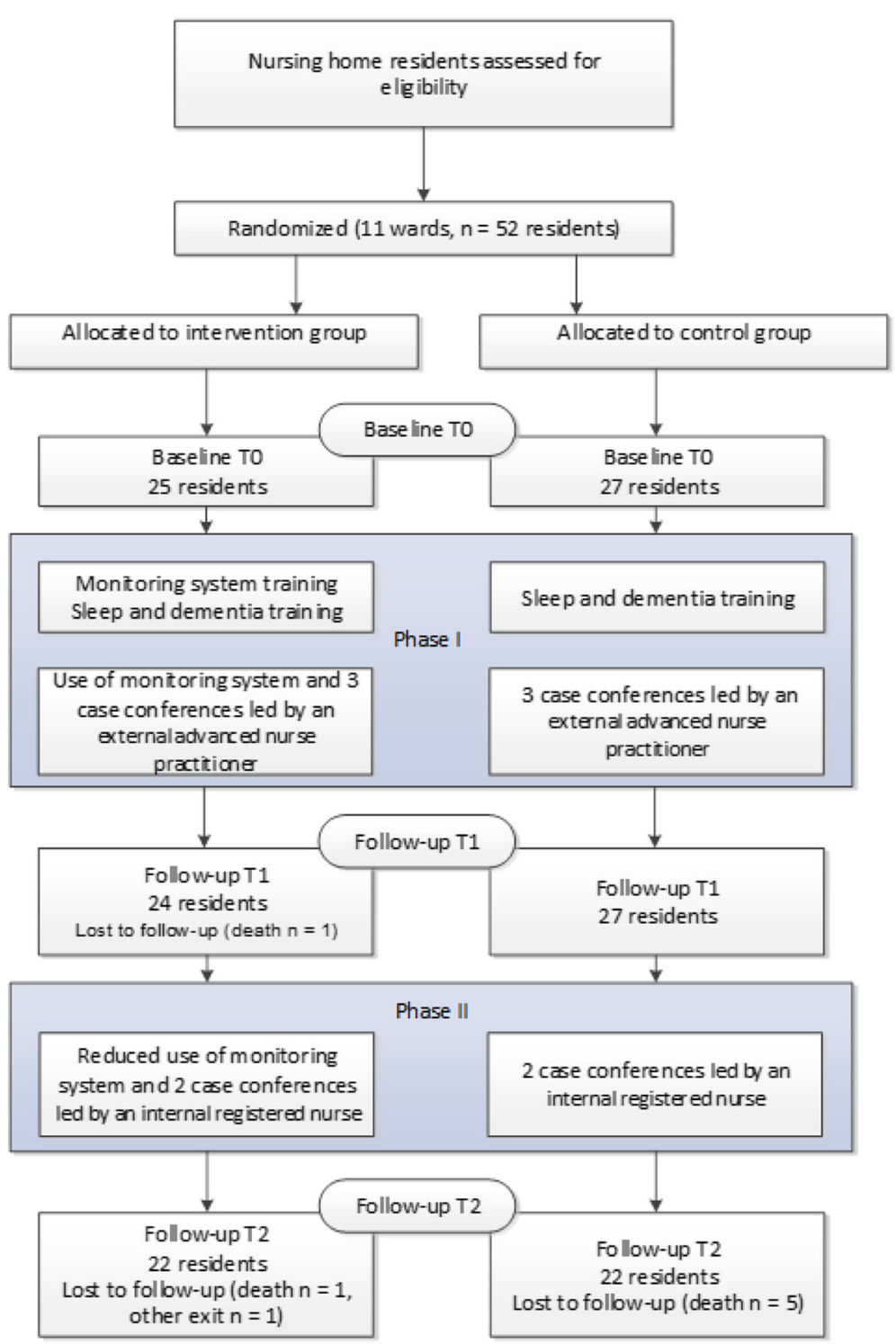

Fig. 2 Study Flowchart. This flowchart shows the flow of interventions and data collection over the presented study as well as number of residents per study phase

\section{Cost calculation of respective care activities}

To calculate the time needed for each of these activities, the average time quoted on the LEP was used [11]. The LEP is a performance classification instrument for the uniform documentation of services in the healthcare sector. This method is consistent with the International Classification of Nursing Practice (ICNP) and the International Standard Classification of Occupations (ISCO).

This information was used to calculate the time spent by nurses caring for the study participants. Finally, based on the actual personnel costs (including nursing home overheads), the total cost of the care activities was calculated (see below "cost of care"). It must be noted that in these study nurses' activities relevant for sleep and activities connected with mobility impairment (e.g. decubitus and fall prophylaxis) were recorded. Other care activities such as support with personal hygiene or nutrition were not included and thus not reflected in the calculation.

\section{Calculation of reimbursement}

The care needs of each participant were assessed at each data collection point (T0, T1, T2). This was done using the assessment instrument normally used at the respective nursing home. This was either BESA (BewohnerInnen EinStufungs- und Abrechnungssystem; for supplier details, see besacare.ch) or RAI-NH (Resident Assessment Instrument - Nursing Home; see rai.ch). 
In the Swiss reimbursement system for elderly care in nursing homes, care levels ("Pflegestufen") are assigned based on a scale of 1 to 12, defined by the activities needed for the specific. These care levels are based on BESA or RAI assessments and define nursing home reimbursement. For instance, the monthly reimbursement for care level 3 is currently CHF 30.10 per day.

\section{Data analysis}

For data analysis IBM SPSS Statistics Version 23 was used. Nurses' activities were assessed over five nights/ days in $\mathrm{T}_{0}, \mathrm{~T}_{1}$ and $\mathrm{T}_{2}$. For the sake of stability, the average of five measured values was used for each activity in each point of time. Sums of activities per night/day were calculated. To account for variation over time (repeated measurement component) as well as between groups (independent sample component: intervention group vs. control group) linear mixed models were employed. Ftests were used to test for differences between the groups (intervention group vs. control group), over time and for interaction. Sphericity was tested by Mauchly's test, using the Greenhouse-Geisser modification in case of violation of Sphericity. We used Kolmogorov-Smirnov tests to assess normality of the dependent variables and calculated Cooks's distances to find out if there are outliers. Single activities as well as the sum of activities were tested for group specific differences (intervention group vs. control group), for changes over time $\left(T_{0}, T_{1}, T_{2}\right)$ and for interactions (group specific evolvement over time). To assess relationships between metric or pseudometric data Pearson correlations were calculated. Tests were performed at a level of significance of 5\%. For sample size calculations we used GLIMMPSE (Kreidler et al. [12]).

\section{Results}

\section{Care activities}

Table 1 shows nurses' caregiving activities. Statistically, average nighttime care activities were reduced significantly in both groups during the first phase. While in the control group the number of activities between T1 and T2 remained approximately the same, the number of nighttime activities in the intervention group increased in the second phase to a level above the initial T0. The number of control visits at night exhibits a statistically significant difference between the measurement points. At T1, both groups show a marked decline in average check-up visits, whereas at $\mathrm{T} 2$ the number of visits increases again. Regarding incontinence care at night, a significantly lower frequency over time (T0 to T2) is shown in the control group. In the first phase, a reduction occurred in the intervention group, whereas in the second phase incontinence care again increased above the starting level at T0.
Daycare activities reveal no statistically significant changes. Only in the number of decubitus prophylaxis can a statistically significant effect be observed over time in both groups. First, there is a reduction in decubitus prophylaxis at $\mathrm{T} 1$, but an increase is observed at $\mathrm{T} 2$, which exceeds the initial value in the intervention group.

\section{Cost of care}

Table 2 shows the average cost of care, calculated based on the activities recorded. No relevant changes occurred from T0 to T1 nor did any differences between the control group and the intervention group.

\section{Reimbursement}

Table 3 reports average reimbursement per resident, calculated based on the care levels assessed using BESA or RAI and the Swiss reimbursement system. No significant difference was found between the two groups. However, a pronounced difference in care levels was identified between $\mathrm{T} 0$ and $\mathrm{T} 1$, driven by growing care needs over time.

\section{Reimbursement and cost of care}

The data shows that the level of care increased both in the intervention group and in the control group during the study. This increase is statistically significant $(\mathrm{F}=$ $6.040, p=0.005)$. This means that nursing home revenues have increased. The care activities at night have also increased ( $\mathrm{F}=5.575, p=0.09)$. Nevertheless, analysis of the recorded activities could not prove that applying the mobility monitor leads to a higher level of efficiency in the care process, which would enable relevant savings in terms of economic outcomes.

There were no significant differences in care expenses between $\mathrm{T} 0$ and $\mathrm{T} 1$ in the intervention group, as well as in the control group during the same period. Differences between the nursing homes regarding the discussed outcomes (cost of care and care levels) could be observed, but were not statistically significant due to the small sample size.

Figure 3 shows the link between care expenses/activities and care level for both the intervention group and the control group at time T0. No correlation could be found between that care level that drives reimbursement and care activities, which, in turn, drive care costs. The same holds true for $\mathrm{T} 1$ and $\mathrm{T} 2$ respectively.

\section{Changes in reimbursement and cost of care}

Next, the changes between care levels and care expenses between T0 and T1 were plotted. Figure 4 compares the difference in reimbursement based on the change of care levels between T0 and T1 (x-axis) and the cost of care (y-axis), calculated by multiplying the recorded hours with personnel costs. The diagonal line indicates where 
Table 1 Recorded activities

\begin{tabular}{|c|c|c|c|c|c|c|c|c|}
\hline & & $\mathrm{F}$ & df & $p$ & Group & TO: MW (SEM) & T1: MW (SEM) & T2: MW (SEM) \\
\hline \multirow[t]{3}{*}{ Sum of activities } & Group & 0,416 & 1 & 0,523 & KG & $7091(0,353)$ & $6255(0,411)$ & $6245(0,595)$ \\
\hline & Time & 5575 & 1670 & ${ }^{*} 0,009$ & IG & $6448(0,361)$ & $5048(0,421)$ & $7114(0,609)$ \\
\hline & Time* Group & 4159 & 1670 & $*^{*} 0,026$ & & & & \\
\hline \multirow[t]{3}{*}{ Check-up visits at night } & Group & 1155 & 1 & 0,289 & KG & $3655(0,155)$ & $3055(0,177)$ & $3218(0,178)$ \\
\hline & Time & 9297 & 2 & ${ }^{*} 0.000$ & IG & $3162(0,158)$ & $2800(0,181)$ & $3305(0,182)$ \\
\hline & Time*Group & 3242 & 2 & ${ }^{*} 0,044$ & & & & \\
\hline \multirow[t]{3}{*}{ Decubitus prophylaxis at night } & Group & 0,044 & 1 & 0,834 & KG & $1309(0,237)$ & $1227(0,234)$ & $1345(0,368)$ \\
\hline & Time & 2550 & 15,900 & 0,097 & IG & $1248(0,280)$ & $0,771(0,240)$ & $1648(0,377)$ \\
\hline & Time*Group & 1475 & 1590 & 0,236 & & & & \\
\hline \multirow[t]{3}{*}{ Support with toilet at night } & Group & 0,066 & 1 & 0,799 & KG & $0.900(0,332)$ & $1082(0,415)$ & $0,836(0,381)$ \\
\hline & Time & 0,126 & 2 & 0.882 & IG & $1210(0,340)$ & $0,848(0,425)$ & $1143(0,390)$ \\
\hline & Time* Group & 1431 & 2 & 0,245 & & & & \\
\hline \multirow[t]{3}{*}{ Incontinence care at night } & Group & 0,895 & 1 & 0,350 & KG & $1227(0,170)$ & $0,891(0,127)$ & $0,845(0,134)$ \\
\hline & Time & 3643 & 2 & $*^{*} 0,031$ & IG & $0,829(0,174)$ & $0,629(0,130)$ & $1019(0,137)$ \\
\hline & Time*Group & 4405 & 2 & $*^{*} 0,015$ & & & & \\
\hline \multirow[t]{3}{*}{ Sum of activities during the day } & Group & 0,646 & 1 & 0,426 & KG & $11,127(1385)$ & $11,827(1289)$ & $12,818(0,935)$ \\
\hline & Time & 1405 & 2 & 0,251 & IG & $12,829(1319)$ & $12,829(1319)$ & $13,781(0,957)$ \\
\hline & Time*Group & 0,048 & 2 & 0,953 & & & & \\
\hline \multirow[t]{3}{*}{ Decubitus prophylaxis during the day } & Group & 0,568 & 1 & 0,455 & KG & $1882(0,407)$ & $1318(0,319)$ & $1755(0,426)$ \\
\hline & Time & 6942 & 2 & ${ }^{*} 0,002$ & IG & $1990(0,417)$ & $1629(0,326)$ & $2495(0,436)$ \\
\hline & Time*Group & 1609 & 2 & 0,206 & & & & \\
\hline \multirow[t]{3}{*}{ Transfer during the day } & Group & 0,520 & 1 & 0,475 & KG & $2609(0,373)$ & $2655(0,517)$ & $2964(0,285)$ \\
\hline & Time & 2137 & 2 & 0,125 & IG & $2495(0,382)$ & $3724(0,530)$ & $2981(0,292)$ \\
\hline & Time*Group & 2142 & 2 & 0,124 & & & & \\
\hline \multirow[t]{3}{*}{ Accompany in room during the day } & Group & 0,051 & 1 & 0,823 & KG & $2392(0,344)$ & $2591(0,222)$ & $2782(0,251)$ \\
\hline & Time & 1046 & 1867 & 0,352 & IG & $2486(0,352)$ & $2343(0,227)$ & $2752(0,257)$ \\
\hline & Time* Group & 0,238 & 1867 & 0,774 & & & & \\
\hline \multirow[t]{3}{*}{ Accompany outside room during the day } & Group & 0,315 & 1 & 0,578 & KG & $2618(0,368)$ & $3018(0,373)$ & $3118(0,273)$ \\
\hline & Time & 0,259 & 2 & 0,773 & IG & $3276(0,377)$ & $2876(0,381)$ & $3162(0,279)$ \\
\hline & Time*Group & 0,915 & 2 & 0,405 & & & & \\
\hline \multirow[t]{3}{*}{ Support toilet during the day } & Group & 0,626 & 1 & 0,433 & KG & $1627(0,290)$ & $2245(0,320)$ & $2200(0,292)$ \\
\hline & Time & 1984 & 2 & 0,144 & IG & $2333(0,297)$ & $2257(0,328)$ & $2390(0,299)$ \\
\hline & Time*Group & 2216 & 2 & 0,116 & & & & \\
\hline
\end{tabular}

$\mathrm{F}=\mathrm{F}$-value, $\mathrm{df}=$ degrees of freedom, $p=p$-value; MW = average, $\mathrm{SEM}=$ standard deviation, ${ }^{*} p$-value $<0,5$

Table 2 Cost of Care in CHF

\begin{tabular}{lllll}
\hline $\begin{array}{l}\text { Average per } \\
\text { resident per } \\
\text { day }\end{array}$ & $\begin{array}{l}\text { Activities in } \\
\text { minutes at T0 }\end{array}$ & $\begin{array}{l}\text { Cost of Care } \\
\text { in CHF at T0 }\end{array}$ & $\begin{array}{l}\text { Activities in } \\
\text { minutes at } \\
\text { T1 }\end{array}$ & $\begin{array}{l}\text { Cost of } \\
\text { Care in CHF } \\
\text { at T1 }\end{array}$ \\
\hline $\begin{array}{l}\text { Control Group } \\
\text { Intervention }\end{array}$ & 206 & 124.59 & 200 & 130.47 \\
\begin{tabular}{l} 
Group \\
\hline
\end{tabular} & 134.45 & 202 & 131.89 \\
\hline
\end{tabular}

Table 3 Reimbursement in CHF

\begin{tabular}{lll}
\hline Average per resident per day & $\begin{array}{l}\text { Reimbursement at } \\
\text { T0 }\end{array}$ & $\begin{array}{l}\text { Reimbursement } \\
\text { T1 }\end{array}$ \\
\hline Control Group & 77.95 & 84.61 \\
Intervention Group & 81.27 & 85.00 \\
\hline
\end{tabular}




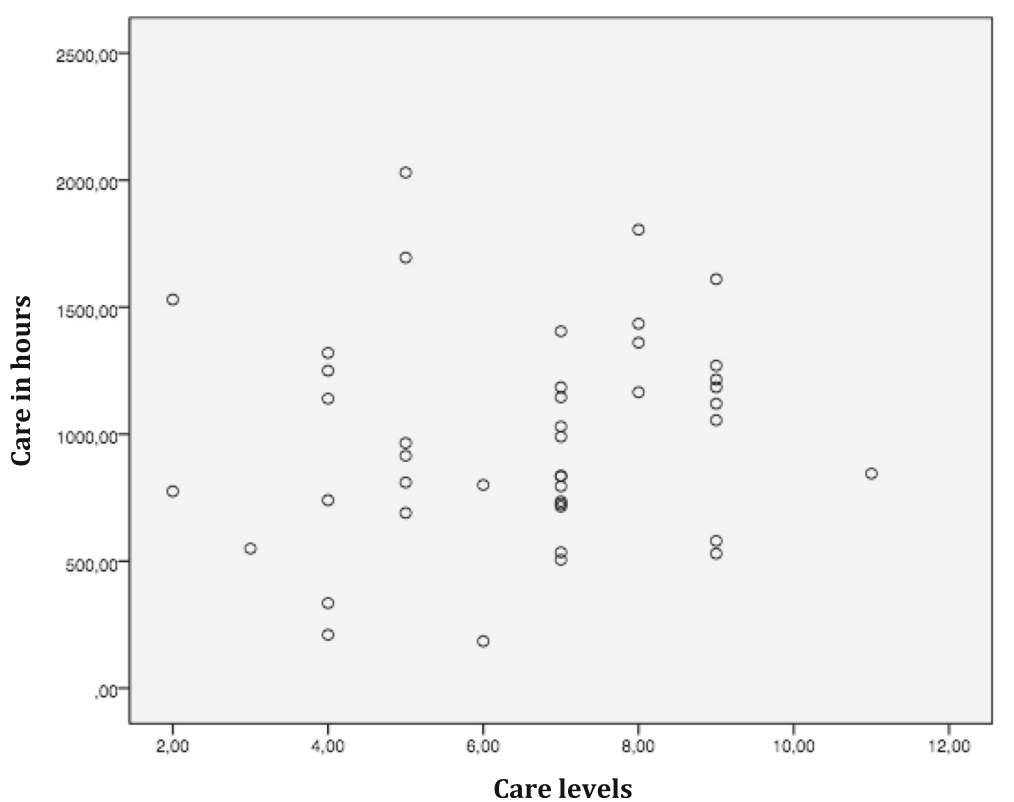

Fig. 3 Relationship between cost of care and reimbursement, for all residents. Relationship between reimbursement, represented by the care levels ( $x$ - axis) and care in hours during 5 days/nights ( $y$-axis), per resident

additional costs are compensated by additional reimbursement. Any data point above the line indicates a resident for whom costs have increased disproportionally compared to reimbursement. Any data point beneath the line indicates a resident for whom the increase in reimbursement was greater that the increase in cost. If revenue (reimbursement minus cost of care) was positive, the data point is marked in green; if negative, in red). Evident are those cases in which the economic situation per resident has improved while in others the situation has deteriorated, i.e., the respective nursing home has increased costs while revenues have remained stable.

\section{Example:}

Table 4 shows that the ratio between cost of care and reimbursement could be improved significantly in specific cases. This was not true in all cases, for instance, when the cost of care was covered by reimbursement whereas the loss per resident was reduced. For example, resident 2A10 needed care at T0 that cost CHF 149.08 per day. Given that only CHF 45.20 were reimbursed, the nursing home lost CHF 103.88 per day. At T1, the reimbursed CHF 45.20 did not cover the present cost of CHF 78.46 per day, but the loss for the nursing home was reduced by CHF 70.62 per day.

\section{Discussion}

In this study, it was sought to assess the influence of the use of a monitoring system accompanied with case conferences on cost of care. The discussion on the economic impacts of applying the mobility monitor in the care process refers mainly to the cost-income balance of the examined nursing homes. The cost situation is reflected in the study by the variable care expenses. It focuses on labor costs and is operationalized by the time needed to execute care activities. Further cost factors, such as material costs and incidental expenses, are not taken into consideration because they only account for a small proportion of the overall costs and were not expected to change significantly in the study. The income situation is reflected by the level of care because this factor determines the reimbursement that nursing homes can claim from health insurances.

The analyzed data exhibit no statistically significant relationship between care expenses and care level. This finding needs to be discussed in more detail. Care expenses were measured retrospectively by the operating nurses and reflect the number of activities to be carried out. Although this measure does not fully cover all the activities of the care process, the outcomes are highly relevant and call for discussion. This is necessary because the outlined limitations apply to all patients and because this study focuses on the overall relationship between care expenses and care level rather than on single activities.

The care level reflects the ex-ante estimated amount of activities needed in the care process of an individual patient. As outlined, care-level determination follows a standardized procedure according to the BESA or the RAI scheme.

From an economic perspective, the missing link between actual care expenses and estimated needs for care activities leaves room for improvement. In current 


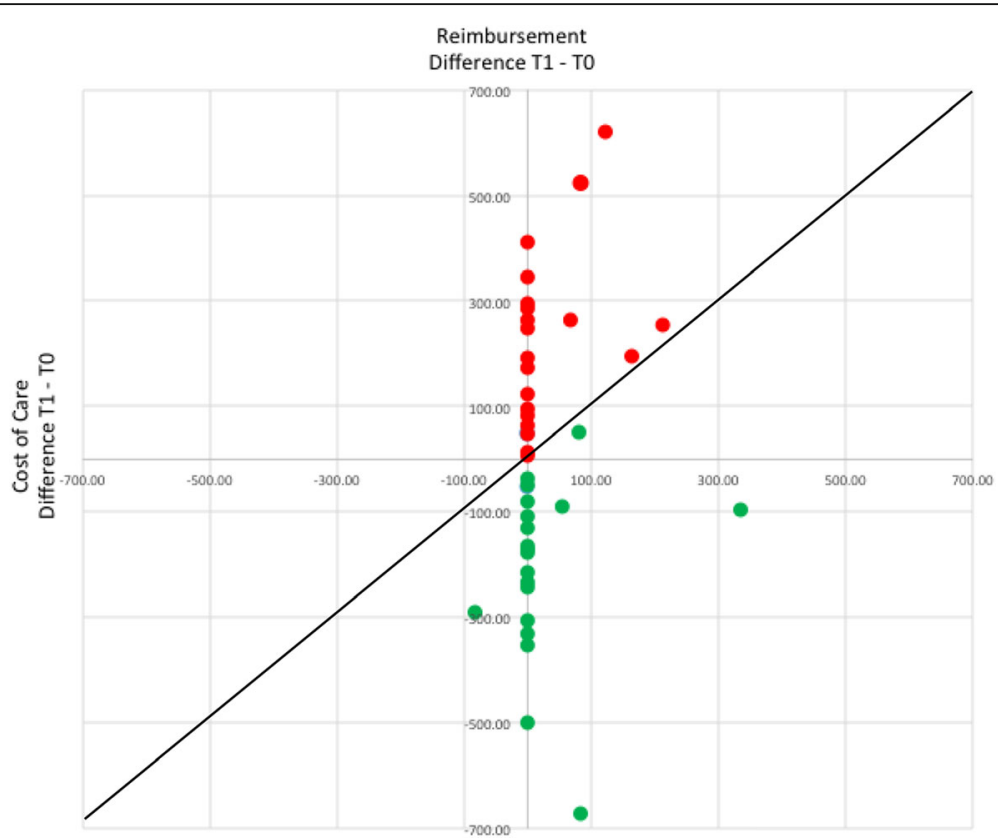

Fig. 4 Changes in Reimbursement and Cost of Care - T0 vs. T1. Changes in cost of care from T0 to T1 versus the changes in reimbursement from T0 to T1, both in CHF. Diagonal line represents the position where additional costs were compensated with additional reimbursement

Table 4 Reimbursement and Cost of Care in CHF per day

\begin{tabular}{|c|c|c|c|c|c|c|c|c|c|c|c|}
\hline \multirow[b]{2}{*}{ Resident } & \multicolumn{5}{|l|}{ TO } & \multicolumn{5}{|l|}{ T1 } & \multirow{2}{*}{$\begin{array}{l}\text { Difference T1-T0 } \\
\text { Profit/loss }\end{array}$} \\
\hline & $\begin{array}{l}\text { Care } \\
\text { level }\end{array}$ & Reimbursement & $\begin{array}{l}\text { Care in } \\
\text { Minutes }\end{array}$ & $\begin{array}{l}\text { Cost of } \\
\text { Care }\end{array}$ & $\begin{array}{l}\text { Profit/ } \\
\text { Loss }\end{array}$ & $\begin{array}{l}\text { Care } \\
\text { Level }\end{array}$ & Reimbursement & $\begin{array}{l}\text { Care in } \\
\text { Minutes }\end{array}$ & $\begin{array}{l}\text { Cost of } \\
\text { Care }\end{array}$ & $\begin{array}{l}\text { Profit/ } \\
\text { Loss }\end{array}$ & \\
\hline $2 \mathrm{~B} 12$ & 5 & 54.70 & 339 & 221.66 & -166.96 & 6 & 71.40 & 499 & 326.28 & -254.88 & -87.92 \\
\hline $4 C 20$ & 7 & 87.70 & 167 & 109.19 & -21.49 & 7 & 87.70 & 273 & 178.50 & -90.80 & -69.31 \\
\hline 2A08 & 7 & 87.70 & 281 & 183.73 & -96.03 & 7 & 87.70 & 362 & 236.70 & -149.00 & -52.96 \\
\hline $4 C 16$ & 9 & 112.10 & 116 & 75.85 & 36.25 & 9 & 112.10 & 192 & 125.54 & -13.44 & -49.69 \\
\hline $2 \mathrm{~A} 12$ & 5 & 54.70 & 162 & 105.93 & -51.23 & 5 & 54.70 & 221 & 144.50 & -89.80 & -38.58 \\
\hline $2 \mathrm{~A} 05$ & 9 & 112.10 & 224 & 146.46 & -34.36 & 9 & 112.10 & 253 & 165.43 & -53.33 & -18.96 \\
\hline $2 \mathrm{~A} 09$ & 9 & 112.10 & 254 & 166.08 & -53.98 & 9 & 112.10 & 274 & 179.16 & -67.06 & -13.08 \\
\hline 1B09 & 8 & 101.20 & 233 & 152.35 & -51.15 & 8 & 101.20 & 248 & 162.16 & -60.96 & -9.81 \\
\hline $4 C 22$ & 5 & 54.70 & 183 & 119.66 & -64.96 & 5 & 54.70 & 187 & 122.27 & -67.57 & -2.62 \\
\hline $4 C 17$ & 4 & 45.20 & 42 & 27.46 & 17.74 & 4 & 45.20 & 27 & 17.65 & 27.55 & 9.81 \\
\hline 1C02 & 7 & 87.70 & 159 & 103.96 & -16.26 & 7 & 87.70 & 143 & 93.50 & -5.80 & 10.46 \\
\hline $4 C 24$ & 7 & 87.70 & 107 & 69.96 & 17.74 & 7 & 87.70 & 83 & 54.27 & 33.43 & 15.69 \\
\hline $4 C 21$ & 5 & 54.70 & 138 & 90.23 & -35.53 & 5 & 54.70 & 98 & 64.08 & -9.38 & 26.15 \\
\hline $2 \mathrm{~B} 11$ & 8 & 101.20 & 287 & 187.66 & -86.46 & 9 & 112.10 & 260 & 170.00 & -57.90 & 28.55 \\
\hline $4 C 23$ & 9 & 112.10 & 106 & 69.31 & 42.79 & 9 & 112.10 & 52 & 34.00 & 78.10 & 35.31 \\
\hline 1B08 & 7 & 87.70 & 229 & 149.73 & -62.03 & 6 & 71.40 & 140 & 91.54 & -20.14 & 41.89 \\
\hline 1C01 & 7 & 87.70 & 198 & 129.46 & -41.76 & 7 & 87.70 & 132 & 86.31 & 1.39 & 43.15 \\
\hline 1B06 & 7 & 87.70 & 237 & 154.96 & -67.26 & 7 & 87.70 & 166 & 108.54 & -20.84 & 46.42 \\
\hline $2 \mathrm{~A} 06$ & 9 & 112.10 & 322 & 210.54 & -98.44 & 9 & 112.10 & 229 & 149.73 & -37.63 & 60.81 \\
\hline $2 \mathrm{~A} 10$ & 4 & 45.20 & 228 & 149.08 & -103.88 & 4 & 45.20 & 120 & 78.46 & -33.26 & 70.62 \\
\hline $2 \mathrm{~A} 04$ & 2 & 20.70 & 306 & 200.08 & -179.38 & 7 & 87.70 & 277 & 181.12 & -93.42 & 85.96 \\
\hline
\end{tabular}


practice, the level of care for an individual patient is adjusted on a regular basis (normally every 6 months) and takes into consideration nurses' observations and written documentation. In this context, the results raise several questions potentially relevant for current practice:

- How can the outlined evaluation process be improved? What can be done that ex ante estimations meet ex post observations? How can this fit be measured in practice?

- What would be the economic impact of an improvement? For whom?

- Missing link: Is there a systematic overestimation or underestimation? Or do discrepancies occur randomly?

- Are there incentives to reduce the care level? Are there incentives to raise it?

- Which incentives exist for nursing homes to improve the process? Is there an economic benefit of doing better?

- Might other stakeholders be affected? (e.g., insurances)

To discuss the outlined questions, case-based examples should be illustrated and discussed in more detail. Data includes several individual cases that exhibit an economically unfavorable path regarding the relation between care expenses and care level as a proxy for the income situation.

In this context, further practically and academically relevant questions can be formulated: How did the procedures and practices regarding the application of the mobility monitor differ in the examined nursing homes? What are the best practices for ensuring the most favorable outcomes?

Notably, significant interaction was observed between time and group: a more pronounced increase in sleep quality was found in the intervention group in T1 (see [10]). Therefore, not only directly cost-driven factors must be considered, but also the quality of care and residents' subsequent quality of life.

The limitations of the study include the small study size that did not allow investigating some effects of the intervention, as well as the cost of medication that was not taken into account. Furthermore, there are limitations in the current care level evaluations systems (BESA/RAI) insofar as the care activities for residents with dementia are not well reflected in the current systems [13]. As a further limitation, the cost of additional tools like security bars or positioning aids were not taken into consideration. The cost of the medication given to residents was not assessed either, given that in the Swiss reimbursement system medication is covered by the health insurance of the individual resident.

\section{Conclusions}

The study results and feedback from the participating nurses suggest a positive overall impact of applying the mobility monitor in the care process (e.g., improved sleep quality). These effects cannot be attributed solely to applying the mobility monitor as a supporting, technology-based information system with hardware and software components. All interventions were combined with nursing care conferences that provided inputs on the care process and on the usage of the mobility monitor device by external and internal nursing experts.

On average, these results demonstrate the presence of a high sleep quality in the examined patients and a highlevel care process at the nursing homes under study. In this context, further improving the aggregated level of these measures might be very difficult and questionable in terms of economic benefits. However, information systems such as the mobility monitor can help to identify single outliers that do not correspond with the overall situation. In the health care system, problematic individual cases can account for a disproportionally high cost levels. It was shown that information systems can have a significant economic impact in the long run.

\section{Acknowledgments \\ This study was funded by the Swiss Federal Commission for Technology and Innovation (grant number KTI-Nr. 16978.1 PFES-ES) and by Compliant \\ Concept, a private company. The funders had no role in the decision to publish this manuscript, or in its drafting and writing.}

Availability of data and materials

All data and material is stored at the University of Applied Science St. Gallen to ensure data privacy.

\section{Authors' contributions}

MS had the overall project management of the study and coordinated all activities. He also wrote chapters 1, 2 and 3 of the article and coordinated the submission of the article. RT performed most economic evaluations of the data gathered in the study and wrote the chapters 4 and 5. HG undertook the day-to-day coordination of the study execution and led as the advanced nurse practitioner most of the case conferences during Phase 1 of the study. $\mathrm{VH}$ was the principal investigator of the study and took care of all regulatory and ethical considerations. SO performed all statistical analysis and tests; he also wrote the chapter 2.7. All authors read and approved the final manuscript.

\section{Ethics approval}

All procedures performed in studies involving human participants were in accordance with the ethical standards of the institutional and/or national research committee and with the 1964 Helsinki declaration and its later amendments or comparable ethical standards. The study protocol was approved by the Ethical Committee of the Kanton St.Gallen, Switzerland (Ref. EKSG14/101).

\section{Competing interests}

The authors declare that they have no competing interests.

\section{Publisher's Note}

Springer Nature remains neutral with regard to jurisdictional claims in published maps and institutional affiliations. 


\section{Author details}

Institute of Business Management, University of Applied Sciences St. Gallen, Rosenbergstrasse 59, Postfach, 9001 St. Gallen, Switzerland. ${ }^{2}$ Institute for Applied Nursing Science, University of Applied Science St. Gallen, St. Gallen, Switzerland. ${ }^{3}$ Statistician, University of Applied Sciences St. Gallen, St. Gallen, Switzerland.

Received: 19 July 2017 Accepted: 2 November 2017

Published online: 01 December 2017

\section{References}

1. Curaviva Herausforderungen und Erfolgsfaktoren für Altersinstitutionen in naher Zukunft Online-Umfrage im Jahr 2009 und 2015 im Auftrag von CURAVIVA Schweiz. 2015 https://www.curaviva.ch/files/W63TPM8/studie_ 2015_zu_herausforderungen_und_erfolgsfaktoren_der_schweizer_ altersinstitutionen.pdf.

2. Federal Statistics Office (2014) Indicators for Swiss nursing homes. https:// www.bag.admin.ch/bag/de/home/service/zahlen-fakten/zahlen-fakten-zupflegeheimen/kennzahlen.html.

3. Crivelli L, Filippini M, Lunati D. Regulation, ownership and efficiency in the Swiss nursing home industry. Int J Health Care Finance Econ. 2002;2:79-97. Kluwer Academic Publishers. The Netherlands

4. Fillipini M. Economies of scale in the Swiss nursing home industry. 1999 www.econ.uzh.ch/static/wp_soi/wp9901.pdf.

5. De Veer AJE, Fleuren M, Bekkema N, Francke AL. Successful implementation of new technologies in nursing care: a questionnaire survey of nurse-users. MC Med Inform Decis Mak. 2011;11:67.

6. Hitt LM, Tambe P. Health care information technology, work organization, and nursing home performance. ILR Review. 2016;69(4):834-59.

7. Rantz M, Lane K, Phillips LJ, Despins LA, Galambos C, Alexander GL, Koopman RJ, Hicks L, Skubic M, Miller SJ. Nurs Outlook. 2015;63:650-5.

8. Beaty JA, Sauer TM. The efficacy of Goodmark Medical's solution using the BAM labs smart bed TechnologyTM in the prevention of pressure ulcers. J Aging Sci. 2014;2(2):1000123.

9. Slight SP, Franz C, Olugbile M, Brown HV, Bates DW, Zimlichman E. The return on investment of implementing a continuous monitoring system in general medical-surgical units. Crit Care Med. 2014;42(8):1862-8.

10. Gattinger $H$, Hantikainen V, Ott St, Stark M. Effectiveness of a mobility monitoring system included in the nursing care process in order to enhance the sleep quality of nursing home residents with cognitive impairment. Health Technol. 2016. DOI 10.1007/s12553-016-0168-9.

11. Baumberger D, Dubach A. Dokumentation LEP nursing 3. Version 1. St Gallen: LEP AG (Hrsg.); 2006.

12. Kreidler SM, Muller KE, Grunwald GK, Ringham BM, Coker-Dukowitz ZT, Sakhadeo UR, Barón AE, Glueck DH. GLIMMPSE: online power computation for linear models with and without a baseline covariate. J Stat Softw. 2013; 54(10):i10.

13. Bartelt, G., Anliker, M. Ergebnisse Pflegeaufwandgruppen - Umsetzung RUGModell. Systeme zur Qualitäts- und Kostensteuerung im Gesundheitswesen. Internal Report. 2016

\section{Submit your manuscript to a SpringerOpen ${ }^{\circ}$ journal and benefit from:}

- Convenient online submission

- Rigorous peer review

- Open access: articles freely available online

- High visibility within the field

- Retaining the copyright to your article 